\title{
A FORMAÇÃo dO PEDAGOGO NA EDUCAÇÁO A DISTÂNCIA: ALGUNS DILEMAS E POSSIBILIDADES
}

\section{THE FORMATION OF THE PEDAGOGUE IN DISTANCE EDUCATION: SOME DILEMMAS AND POSSIBILITIES}

\author{
Adriana Regina de Jesus Santos \\ Doutora em Educação pela Pontifica Universidade Católica de São Paulo. \\ Docente na Universidade Estadual de Londrina. Paraná. PR. Brasil. \\ adrianatecnologia@yahoo.com.br
}

José Alexandre Gonçalves Mestrando em Educação pela Universidade Estadual de Londrina. Professor da Rede Estadual de Ensino no Estado do Paraná. Paraná. PR. Brasil. alexandregeopg@gmail.com

Rogério da Costa Doutorando em Educação pela Universidade Estadual de Maringa. Docente do curso de Pedagogia da UNIVALE e professor da rede estadual de ensino de Londrina. ipbrogerio@yahoo.com.br

\begin{abstract}
Resumo: O referido artigo tem como objetivos compreender o perfil da formação do pedagogo e conhecer as diferenças de intencionalidade em relação a "Objetivos" e "Perfil de Egresso" que os programas pretendem formar, tendo como parâmetro dois cursos de Pedagogia, ofertados na modalidade de $\mathrm{EaD}$, por uma instituição pública e outra privada, localizados na cidade de Telêmaco Borba, PR, bem como analisar as percepções dos acadêmicos em relaçáo a sua formação no que tange ao compromisso ético-profissional. Como procedimentos metodológicos adotamos a revisão de literatura, levantamento documental e trabalho de campo. Na revisão de literatura, tivemos como suporte teórico alguns autores, tais como: Freire (1983), Giroux (1992), Lessa (2012), Lukács (2013), Nóvoa (1992), Pimenta (1999), Saviani (2005), entre outros; na pesquisa documental analisamos dois projetos pedagógicos dos referidos cursos e como trabalho de campo aplicamos um questionário para coleta de dados junto aos estudantes das duas instituiçôes. Ao término do estudo, constatou-se certa ambiguidade no que se refere à formação do perfil do pedagogo que se almeja formar, dado que na faculdade particular o foco estava voltado à empregabilidade desse profissional no mercado de trabalho e na instituição pública percebeu-se a preocupação com a formação ontológica, ética e política do futuro profissional pedagogo.
\end{abstract}

Palavras-chave: Educação a Distância. Empregabilidade. Ontologia. Pedagogo.

AвSTRACT: The objective of this article is to understand the profile of the education of the pedagogue and to know the differences of intentionality in relation to the "Objectives" and "Profile of Egresso" that the programs intend to form, having as a parameter two courses of Pedagogy offered in the modality of EAD, by a public and a private institution, located in the city of Telêmaco Borba, PR, as well as to analyze the perceptions of the academics in relation 
to their formation regarding the ethical-professional commitment. As methodological procedures we adopted the literature review, documentary survey and field work. In the review of literature, we have as theoretical support some authors, such as Freire (1983), Giroux (1992), Lessa (2012), Lukács (2013), Nóvoa (1992), Pimenta (1999), Saviani among others; in documentary research we analyzed two pedagogical projects of the mentioned courses and as field work we applied a questionnaire for data collection with the students of both institutions. At the end of the study, there was a certain ambiguity regarding the formation of the profile of the pedagogue that is sought to form, given that in the private faculty the focus was on the employability of this professional in the labor market and in the public institution. concern with the ontological, ethical and political formation of the future professional pedagogue.

KeYwords: Distance Education. Employability. Ontology. Pedagogist.

\section{Introduçáo}

Esse artigo é a objetivação de um estudo sobre a formação do pedagogo, tendo como parâmetro dois cursos de Licenciatura em Pedagogia na modalidade a distância $(\mathrm{EaD})$ desenvolvidos na cidade de Telêmaco Borba, PR. O primeiro curso é oferecido pela Faculdade Anhanguera Educacional, instituiçấo privada do grupo Kroton Educacional que possui polos de apoio presencial em várias cidades do país; o segundo é ofertado pela Universidade Estadual de Ponta Grossa(UEPG), que por meio do Programa Universidade Aberta do Brasil (UAB) possui polos em várias cidades do Paraná. A partir da apreciação dos projetos pedagógicos dos cursos, foi possível verificar dados concretos que distinguem completamente os dois cursos dessa modalidade e que formam pedagogos na mesma cidade paranaense.

O objetivo da pesquisa teve como proposito compreender o perfil da formação do pedagogo e conhecer as diferenças de intencionalidade em relação a "Objetivos" e "Perfil de Egresso" que os programas pretendem formar, tendo como parâmetro dois cursos de Pedagogia, ofertados na modalidade $\mathrm{EaD}$, por uma instituição pública e outra privada, localizados na cidade de Telêmaco Borba, PR, bem como analisar as percepçóes dos acadêmicos em relação a sua formação no que tange ao compromisso ético-profissional. Para tanto, além da referida apreciaçáo documental, procedemos à coleta de dados por meio de um questionário aplicados aos estudantes dos cursos em questão, tendo como finalidade 
identificar como estes percebem sua formação no que tange ao compromisso ético-profissional.

Justifica-se tal preocupação por entender que o professor pedagogo necessita ser capaz de fazer uma leitura do mundo e ter consciência do seu papel crítico no que tange à organização do trabalho pedagógico, bem como das relaçôes de trabalho, das transformaçôes recentes da economia global e de suas influências no campo da Educação.

Isso posto, o conceito-chave que nos auxilia a compreender a questão da consciência e do compromisso político do pedagogo tem relação com a questão da ontologia do ser social, conforme desenvolvida por György Lukács. Para esse autor, o ser social "se particulariza pela incessante produçáo do novo, por meio da transformação do mundo que o cerca de maneira conscientemente orientada, teleologicamente posta." (LUKÁCS apud LESSA, 2012, p.

25). Nesse sentido, buscamos compreender o perfil da formação do pedagogo, para refletir sobre a ontologia do trabalho desse profissional como um trabalho intencionalizado, idealizado conscientemente e objetivado, visando à produção do novo, à transformação. Para Lukács (2013), o ser social se caracteriza por constituir um complexo de complexos. Desse processo de transformar e se transformar por meio do trabalho, que é a essência do ser humano na construção da cultura, surge uma necessidade: educar-se. Esta tem por finalidade a reprodução do ser social. A compreensão desse carácter ontológico da Educação, Saviani (2005) vem elucidar, quando define que, "consequentemente, o trabalho educativo é o ato de produzir, direta e intencionalmente, em cada indivíduo singular, a humanidade que é produzida histórica e coletivamente pelo conjunto dos homens." (SAVIANI, 2005, p. 12). Isto posto, a intenção do trabalho educativo é produzir a humanidade nos indivíduos pela mediação saberes historicamente acumulados.

Dedicamo-nos à referida noção de ontologia do trabalho para relacioná-la com suas repercussôes na práxis ${ }^{1}$ pedagógica, ou seja, ao analisar os programas dos dois cursos de licenciatura de pedagogia, na modalidade a distância, tem-se a possibilidade de indagar sobre os dilemas e perspectivas da formação docente na construção da identidade dos estudantes em formação. Para Pimenta (1999), o campo da formação de professores se insere em novo paradigma que emergiu em vários países nas últimas 
décadas, apresentando pesquisas relacionadas à teoria e à prática docente, desenvolvimento profissional do professor e papel social da docência, compreendendo o professor reflexivo como um intelectual comprometido com o projeto emancipatório dos sujeitos.

Uma indagação que fazíamos e nos motivou a tratar a temática da formação do professor na perspectiva crítica, buscando conhecer se ela está sendo proposta na modalidade da $\mathrm{EaD}$ foi a seguinte: teriam os cursos de Pedagogia a distância o objetivo da formaçáo do professor reflexivo, crítico e transformador da realidade?

Nóvoa (1992), explica que "não há ensino de qualidade, nem reforma educativa, nem inovação pedagógica sem uma adequada formação de professores." (NÓVOA, 1992, p.9). No mesmo ano, Giroux discute em um capítulo de seu livro o fato de que está na formação um dos aspectos que explicam a alienaçãa ${ }^{2}$ do professor frente a sua responsabilidade com a escola, com o currículo, como também seu nível de compromisso com a luta dos trabalhadores da educação; o fato é que as instituições de ensino se omitem na tarefa de formar o professor enquanto um intelectual transformador. (GIROUX, 1992)

A formação de docentes na modalidade a distância tem se tornado

,
há mais de dez anos uma política pública no Brasil e em diferentes países, e também se apresenta como um grande mercado para as instituiçôes privadas. Por isso, entendemos que é necessário produzir análises críticas em relaçáo ao processo de formação de professores nessa modalidade de ensino para contribuir com o debate epistemológico sobre o campo.

Um ponto que se destaca é a recente ampliação do número de egressos dos cursos de pedagogia na modalidade $\mathrm{EaD}$, em polos de formação presentes em várias cidades do estado do Paraná. Uma justificava para tal, está no fato que a formação por intermédio da $\mathrm{EaD}$ serve de instrumento para a democratização do acesso de um número maior de indivíduos ao ensino superior. Com o intuito de refletir sobre o que foi exposto até o momento, partiremos para a análise documental comparativa de projetos pedagógicos, para discutir sobre objetivos e perfis profissionais que orientam a formação em dois cursos de licenciatura em pedagogia na modalidade Educação a Distância, ofertados em polos de apoio presenciais na cidade de Telêmaco Borba-PR. 


\section{Cursos de Pedagogia em EAD: objetivos de formação}

A apreciação documental que nos propomos realizar foi sobre os itens "Objetivos" e "Perfil do Egresso", tópicos descritos nos projetos pedagógicos de cursos. Nosso trabalho foi analisar os planos de curso, buscando identificar se os cursos almejavam, em suas propostas, o objetivo de formar o professor reflexivo, crítico, sujeito comprometido com o projeto emancipatório. (PIMENTA, 1999)

As instituições apreciadas foram a Universidade Estadual de Ponta Grossa (UEPG), instituição pública que oferece a licenciatura em Pedagogia por meio do convênio entre a Universidade Aberta do Brasil (UAB) e a Prefeitura Municipal, e que atende com polo na cidade desde 2008. A outra instituição, a Faculdade Anhanguera Educacional, pertencente ao grupo internacional Kroton Educacional, que no Brasil atua na gestão de várias faculdades na modalidade de ensino presenciais e principalmente na oferta da modalidade EaD. Em Telêmaco Borba-PR, essas instituiçóes estão há quase uma década formando professores. Existem outras instituiçôes que ofertam licenciaturas na modalidade da $\mathrm{EaD}$ na cidade, no entanto, essas duas, já formaram um número expressivo de pedagogos que atualmente se encontram trabalhando nas escolas da região, sendo portanto, UEPG e Anhanguera, as instituiçóes que estão há mais tempo habilitando para as Licenciaturas mediante tal modalidade.

A especificidade da pesquisa em relação ao curso de pedagogia se deu pelo fato de que muitos pedagogos, além de trabalharem como professores no Ensino Fundamental, podem trabalhar na administração, planejamento, supervisão e ainda podem atuar na docência em cursos de formação de professores, modalidade normal do ensino médio, lecionando as disciplinas pedagógicas. Por se tratar de uma função de destaque que o pedagogo possui na escola no que tange à administração e ao ensino, é extremamente importante o seu papel na formação do cidadão consciente. Para isso, o mínimo que se pode esperar é que esse profissional tenha uma compreensão crítica da realidade educacional e social. Contribuindo com essa reflexão, Freire (2205) afirma que o profissional da educação necessita ter visão crítica do mundo social e educacional, pois é sua responsabilidade enquanto sujeito na História. É de longa data que o autor nos ensina que 
"este compromisso não pode realizar-se através do palavrório. O compromisso só existe no engajamento com a realidade." (FREIRE, 1983, p. 18)

As informaçôes relativas aos projetos pedagógicos dos cursos, seus objetivos, perfil de egresso e grade curricular foram retiradas de fontes de domínio público, divulgadas nos sites das duas instituiçôes formadoras. Nossa intenção não foi avaliar a qualidade, mas sim discutir o perfil de formação do pedagogo em ambiento $\mathrm{EaD}$, analisando os documentos que regem tal formação, podendo dessa forma fazer um comparativo entre as instituiçóes de ensino que oferta esta modalidade no espaço publico e privado, desenvolvido em uma mesma localidade.

Desse modo, a Licenciatura em Pedagogia da UEPG, de acordo com seu Projeto Pedagógico de urso, visa oferecer:

[...] formação do profissional de Pedagogia, com determinados saberes que o levem à reflexáo e análise da realidade, vinculando questôes sociais e educativas. Atuação com ética e compromisso com vistas à construção de uma sociedade justa e igualitária. (UNIVERSIDADE ESTADUAL DE PONTA GROSSA, 2016).

É possível perceber nesse objetivo, a intenção de formar um sujeito com uma compreensão ontológica do trabalho. Ontologia esta que para Lukács (2013), se refere à 'essência do ser', que no caso do homem, tanto no âmbito individual quanto genérico, de "Ser Social", tem o trabalho como mediador das relações, sendo ele um ato intencional de criação, construção, transformação. Assim o objetivo proposto no referido curso tem, no plano aparente do documento, a intenção de mediar uma formação na perspectiva ontológica do trabalho docente quando menciona aspectos da totalidade da realidade social e uma atuação que busque a "construção de um sociedade justa e igualitária." Essa é uma perspectiva interessante de formação, pois o conceito está ligado ao processo de tomada de consciência que só o ser humano possui em relação ao seu 'fazer e ser' no meio social, que se materializa na ação, no trabalho intencionalizado, conscientemente 
idealizado, que se objetiva na transformação, na produção do novo, na constante construção da sua existência (LUKÁCS, 2013).

Nesse caso, o curso organizado em oito semestres, constatamos no plano aparente, que este pretende formar um profissional da Educação comprometido com a sociedade, usando do exercício da reflexão crítica para se posicionar frente à sociedade de classes, injusta e desigual, com vistas a sua transformação.

No currículo do curso de Pedagogia da instituição pública analisada, três disciplinas nos chamaram a atenção às quais apresentamos como exemplo: Trabalho e Educação; Educação, Diversidade e Cidadania; Violência e Indisciplina na Escola. Por meio da ementa dessas disciplinas, percebemos que estas procuram discutir aspectos da totalidade educacional, abordando determinados fatores que condicionam o trabalho do pedagogo na escola. Entendemos que essas disciplinas também, permitem ampliar as possibilidades de mediar temas essenciais para formar intencionalmente o sujeito ativo, participativo, ou seja, com uma visão do todo da escola, seus condicionantes internos e externos, que permite o desenvolvimento da consciência crítica em relação ao mundo do trabalho no qual se estabelece sua profissão.

Em relação ao curso de Licenciatura em Pedagogia ofertado pela Faculdade Anhanguera Educacional, no que se refere ao objetivo do curso, constatamos por meio da proposta curricular disponibiliza na página virtual da instituiçãao, que este, está organizado em sete semestres (três anos e meio), e tem como objetivo formar "o pedagogo capacitado a desenvolver práticas pedagógicas e de gestão educacional, promovendo a aprendizagem de quem esteja em diferentes fases do desenvolvimento humano." (ANHANGUERA, 2016). Sobre o perfil do egresso, que consta na mesma página virtual, vemos que

[...] o curso possibilita a formação de um educador pronto para atuar em espaços escolares e não escolares, utilizando as novas tecnologias de informação e comunicação, focando sua atuação no trabalho coletivo. (ANHANGUERA, 2016)

Para tanto, o projeto do curso pretende capacitar para a atuação prática, possibilitando a formaçáo de habilidades para o uso das ferra- 
mentas da era da informática e de um profissional que se adapte ao trabalho coletivo. Comparando com o objetivo do curso de Pedagogia da instituição pública apresentado anteriormente, não se verifica intenção de trabalhar os saberes articulando-os com a reflexão e análise da realidade social e sua transformação. Pelo que se percebe, no plano teórico, o foco do curso da instituição privada limita-se ao indivíduo e ao seu desenvolvimento pessoal.

A página virtual do curso apresenta o pedagogo como tendo a possibilidade de atuação em vários segmentos além da escola, como empresas e rede hospitalar:

Sua atuação é passível em vários segmentos compatíveis com a formação obtida no curso. Por exemplo, na rede hospitalar, que os contrata para trabalhar em suas brinquedotecas desenvolvendo atividades que proporcionem o bem-estar de crianças doentes; na pesquisa científica; entre outros. (ANHANGUERA, 2016) 
Entretanto, na instituição privada é possível perceber que o curso se reveste de um ideal de praticidade, utilitarismo. Em sua explicitação político-pedagógica vemos uma intenção muito evidente de capacitar os estudantes para o 'ter', ou seja, objetiva instrumentaliza-los para a acirrada competição no mercado de trabalho. Desse modo, o futuro profissional terá como maior preocupação o pensar em si, ser eficiente em cumprir o que dele se espera, programar-se para reproduzir um currículo que foi por outros pensado. Tecendo críticas a essa maneira de conceber o curso, Giroux (1992, p. 61) defende uma formação mais humana dos docentes, argumentando que,

Dentro deste discurso, os professores podem ser vistos não simplesmente como operadores profissionalmente preparados para efetivamente atingirem quaisquer metas a eles apresentadas. (GIROUX, 1992, p. 161)

O autor explica que as instituiçôes de formação de professores precisam buscar formar para o "ser" docente, o que envolve outro olhar sobre o curso e os sujeitos em formação. Esses devem serem vistos, como homens e mulheres livres, e sua formaçáo deve se dedicar a valores do intelecto, abordando temáticas que fomentem a capacidade crítica, para que projetem o seu trabalho entendendo-o como parte do todo social, cientes de sua responsabilidade ético-profissional (GIROUX, 1992).

\section{A manifestação dos sujeitos em formação}

Depois dessa primeira tarefa de análise comparativa dos projetos dos cursos, dedicamo-nos à coleta de dados junto aos sujeitos em formação, na intenção de conhecer suas visôes em relação ao curso e sua futura profissão. A coleta dessas informaçôes foi realizada por meio de um questionário distribuído em igual quantidade nas duas instituiçôes, para alunos do $3^{\circ}$ ao $5^{\circ}$ semestres dos cursos, que constavam naquele momento com 35 alunos em processo de formação. A adesáo a participação da pesquisa foi livre, sendo assim, tivemos o consentimento de 20 estudantes que estavam presentes no polos de apoio presencial no dia 
da coleta. Por questóes éticas resguardamos o sigilo de não identificar o vínculo institucional dos acadêmicos.

As questóes focaram na trajetória de formação acadêmica, nas perspectivas profissionais, no mundo do trabalho do professor e o papel da educação na sociedade contemporânea. Pensamos esses temas por acreditar que compreendem aquilo que Giroux (1992) entende ser uma formação docente que se proponha a formar o professor como um intelectual transformador, aquele que reflete e age politicamente.

No levantamento inicial de dados, constatou-se que, nos cursos de licenciatura em Pedagogia EaD ofertados em Telêmaco Borba, PR, pelas instituiçôes objeto de estudo, $75 \%$ dos alunos participantes da pesquisa, já trabalhavam na escola como professor ou funcionário desde 2016 e já tinham uma formaçáo inicial (curso normal ou licenciatura) e apenas 25\%, mais jovens, estavam cursando sua primeira formação.

A primeira questão apresentada aos estudantes em relação à sua formação foi a seguinte: "Você percebe que o curso procurou formar professores autônomos, conscientes e criticos?" Justificamos essa pergunta com base nas referências de importantes autores (FREIRE, 2005; GIROUX, 1992; NÓVOA, 1992; PIMENTA, 1999, etc.), que argumentam sobre a necessidade da formação de professores autônomos, conscientes e com responsabilidade social. Quatro eram as opçôes de respostas: "Muitas vezes"; "Sempre"; "Nunca" e "às vezes". As manifestaçóes dos participantes foram apreciadas e classificadas em dois grupos ou níveis: satisfatório (muitas vezes; sempre) e insatisfatório (nunca, às vezes).

Dessa forma, as manifestações em relação a questão apresentada revelaram que, para $65 \%$ dos participantes, o curso satisfaz suas expectativas em relação a formação crítica do pedagogo. Assim, constatou-se que a maioria vê o curso como positivo em relação a sua intencionalidade do desenvolvimento da autonomia e criticidade. Contudo, para 35\% o curso não satisfaz o objetivo de formar professores autônomos, conscientes e críticos, fato também importante, pois reflete uma postura questionadora por parte desses participantes da pesquisa quanto à sua formação, ou seja, ao confrontar e problematizar a experiência obtida no curso de formação, esses estudantes, foram capazes de avaliar a teoria e a prática que lhe foi ofertada; reconhecendo suas limitaçóes, o que poderá buscar novos saberes para superarem certas fragilidades em sua formação. 
Na sequência, a questão se referia à ocorrência de discussão no curso de Pedagogia de temas importantes para o desenvolvimento do compromisso ético-político do professor, buscando abranger as dimensóes social, política e sindical desses futuros trabalhadores da educação. Apresentamos aos participantes da pesquisa a seguinte pergunta: "A sociedade capitalista, o Estado, a politica, os movimentos sociais e dos trabalhadores foram em algum momento discutidos no seu curso de formação?". Seguindo o mesmo padrão de questionário e de opçóes para respostas, constatou-se que a manifestação mais assinalada foi a opção "às vezes", registradas por $70 \%$ dos estudantes. Entretanto, para outros 30\% dos entrevistados, o curso atende todas as expectativas, pois segundo os participantes, os professores traziam para as aulas temas relacionados ao cotidiano escolar.

Propusemos tal questáo porque no currículo dos dois cursos há disciplinas que promovem a discussão sobre as relaçóes entre sociedade e educação, como por exemplo a disciplina de "Trabalho e Educação", desenvolvida no curso da instituição pública investigada e a disciplina de "Ética, Politica e Sociedade", desenvolvida na instituição privada. Além disso, ela se justifica porque entendemos que o "essencial para a categoria de intelectual transformador é a necessidade de tornar o pedagógico mais político e o político mais pedagógico." (GIROUX, 1992, p.163).

Ainda relacionada ao compromisso ético-político do pedagogo, para conhecer as perspectivas dos participantes da pesquisa no que tange ao mundo do trabalho do professor e em relação à responsabilidade dos docentes e de suas entidades de classe nas lutas do magistério, foi realizada a seguinte pergunta: "Para que ocorram melhorias no campo educacional e que os educadores possam ser bem sucedidos em suas carreiras e salários, é imprescindível a participação dos: governantes; cidadãos; trabalhadores organizados; sem opinião formada. Muitos participantes não assinalaram nenhum item. Aqueles que o fizeram que representa $60 \%$, apontaram que a responsabilidade pela melhoria na carreira e nos salários é dos políticos (governantes) ou da sociedade (cidadãos). Um fato que chamou a atenção, é que nenhum participante da pesquisa assinalou o item relacionado a participação dos docentes e de suas entidades de classe (trabalhadores organizados) o que pode indicar que estes não percebem a importância da participação do professor como sujeito que reivindica seus direitos em relação as melhorias no campo educacional. 
Os dois cursos de licenciatura analisados possuem disciplinas que permitem a possibilidade de discutir esses temas. Contudo, constatou-se, nessa questão, a alienação em transferir a outrem a responsabilidade que o professor deve ter em relação a sua carreira profissional. Sobre a importância desse compromisso, Freire (2005) justificava que "a luta dos professores em defesa de seus direitos e de sua dignidade deve ser entendida como um momento importante de sua prática docente, enquanto prática ética." (FREIRE, 2005, p. 66). Dessa maneira, os cursos que propõem a formação do professor crítico-reflexivo não podem se omitir da responsabilidade de discutir tais temas.

Ainda se referindo a questôes do mudo do trabalho docente, apresentamos uma questáo dissertativa questionado se eles conheciam as entidades que representam a categoria profissional dos professores?" Justificamos tal questão por entender que o tema é fundamental, pois está vinculada ao questionamento anterior e, principalmente, porque está relacionado com o compromisso político do docente, que se vê como sujeito pertencente a uma categoria. De acordo com as informações coletadas, o sindicato dos professores é conhecido por $75 \%$ dos participantes. Como já relatado, constatou-se o mesmo percentual de participantes que estavam na graduação, mas já trabalhavam na educação. Apenas 25\% afirmaram não conhecer as entidades que representam a categoria dos educadores. Esses que afirmam não conhecer as entidades de classe nos remete a pensar $o$ porquê do desconhecimento? Seria por falta de interesse? Ou o curso não proporciona essas reflexóes? Essa reflexão surgiu pois, no atual contexto social e político, os movimentos dos trabalhadores em educação estão em evidência nas mídias por suas constantes lutas em busca de garantir e manter seus direitos.

Diante do exposto sobre a formação do pedagogo na modalidade a distância, fica claro um dilema que pode marcar o perfil do profissional egresso do curso e refletir nele. Essa é a ambiguidade que se coloca na formaçáo docente, que é, por um lado, o desenvolvimento das capacidades ou competências para se ter emprego e se manter empregável, e, por outro, desenvolver os saberes e o compromisso para o Ser docente e assumir, junto aos alunos, à escola e à comunidade, a responsabilidade com o projeto de mudança social. 


\section{Consideraçóes finais}

A partir dessa discussão sobre os cursos de Licenciatura em Pedagogia na modalidade EaD, comparados os universos de uma universidade pública e uma privada, buscou-se compreender a importância da formação do pedagogo voltada para a construção de uma visão ontológica do trabalho docente e da escola como práxis transformadora. Somente essa visão ontológica do trabalho, como defendem vários autores, poderá dar condiçóes de o futuro docente realizar uma 'leitura de mundo' que venha ao encontro dos anseios de mudança da realidade existente - que se apresenta excludente e injusta - por qual passa a maioria dos indivíduos na sociedade capitalista contemporânea. Só quem possui certo nível de consciência consegue ter e sustentar posiçôes que podem subverter a lógica do capital. (FREIRE, 2005)

Expondo as duas propostas de cursos na intencionalidade de formar o Ser professor, revelaram-se ambiguidades. Ouvidos os estudantes, tivemos a possibilidade de sistematizar o que pensam e de refletir acerca do problema inicial que motivou esta pesquisa: a questáo da identidade do pedagogo, de se reconhecer enquanto sujeito, de ter consciência e se envolver nas lutas do magistério, isto é, a formação inicial do compromisso ético e político. Buscamos discutir a importância de ofertar uma formação que busque promover a alteridade, a consciência e a criticidade nos acadêmicos, futuros professores, para com as questóes relativas ao mundo do trabalho. Nesse ponto, afirmamos que as instituiçóes públicas são essenciais, pois não valorizam a formação educacional como mercadoria, o que nos leva a propor que a oferta pública de cursos na modalidade a distância deve ser ampliada e sempre incentivada com políticas públicas que visem mais acesso.

Entretanto, o que vemos é uma acentuada ampliação dos cursos privados de licenciatura na modalidade a distância, que, por força do mercado, chegam a lugares longínquos para vender o seu produto. Esse fato reflete no profissional que chega à escola, pois alguns cursos $\mathrm{EaD}$, como foi possível perceber, mais 'coisificam' o indivíduo do que os humanizam para serem sujeitos e agentes de transformaçáo. Podemos dizer que tais cursos que formam para o 'Ter", mesmo apresentando disciplinas para tratar a temática de 'Ser', apresentam defasagem em temas relacionados à Filosofia 
e à Sociologia da Educação, essenciais para debater o papel do professor e da escola na sociedade e por abrir possibilidades para as discussóes sobre o importante e atual tema que é a carreira do magistério e suas lutas.

Quando se fala em formar o profissional para o mercado, a intenção está em desenvolver e potencializar qualidades para que os indivíduos se mantenham empregáveis, que sejam flexíveis e se adaptem às oportunidades onde elas surgirem. Aí está um perfil de profissional mais passivo, contemplativo, mais disposto a consentir e permitir do que se indignar e questionar. $\mathrm{O}$ grande perigo de haver cada vez mais indivíduos agindo assim é que o único compromisso deles será o pensar em si próprio.

Hoje, mais do que nunca, cabe à formação inicial a instrumentalização do professor para que este seja capaz de desenvolver a consciência crítica, percebendo as contradiçóes nas relaçóes de trabalho, nas transformaçôes recentes da economia global e seus interesses e impactos na educação. Formar um professor em uma perspectiva ontológica do seu trabalho buscará, por exemplo, reconhecer que um saber necessário à práxis do futuro professor é que este conheça sobre o magistério e tenha compromisso com suas lutas. (FREIRE, 2005)

O presente trabalho foi uma provocação dirigida a repensar a formação dos pedagogos na modalidade a distância, seja esta na instituição pública ou privada, ou seja, é imprescindível que nesses cursos sejam abordados a necessidade de propor uma formação que emancipe o sujeito. Essa modalidade de ensino, vem crescendo no país nos últimos anos, elevando os números de formandos e dando oportunidade de trabalho a muitas pessoas, porém pensamos que nossa preocupação não pode ser voltada somente com a quantidade de futuros profissionais, mas sim que os cursos ofertados na modalidade EAD tenham como princípio a formação humana, emancipada, critica e autônoma dos futuros profissionais da educação e que estes possam compreender a importância do ser e o fazer docente no contexto da sociedade contemporânea.

Sabemos da complexidade que envolve a formação do Pedagogo no que se refere aos saberes necessários à sua práxis docente, e um dos desafios centrais é garantir na matriz curricular por meio das disciplinas a formação de um profissional consciente, participativo, que reconheça o carácter teleológico do seu trabalho (PIMENTA, 1999). Isso trará reflexos na ação do ser e do saber docente, o que implicará na construção de um identida- 


\section{de profissional comprometida com o contexto social e educacional, o que contribuirá no processo de ensino e aprendizagem.}

\section{Notas}

1 Práxis, como nos apresenta Sanches Vasquez em seu livro Filosofia da Práxis, é entendida como uma atividade material, transformadora-criadora e ajustada a objetivos. O objetivo é o resultado real de um processo que tem seu ponto de partida no resultado ideal (finalidade). Portanto, o conceito de práxis difere do conceito de prática, pois esta última é uma ação que se realiza constantemente sem reflexão, ao contrário da práxis, que é uma ação planejada de transformação, fundamentada na teoria.

2 Conceito que está diretamente ligado ao trabalho (processo de produção) no qual o indivíduo, envolto em uma série de fatores, limita-se à execução de uma tarefa mecânica em que as decisôes não estão ao seu alcance e os procedimentos são ditados por outrem. Por isso, o indivíduo não se reconhece no produto do seu trabalho, não se vê como um agente que tem a possibilidade de criar e fazer diferente. Para o melhor entendimento desse conceito, ver as obras de Alcântara (2014), Codo (1985), Giroux (1992) e Lukács (2013).

\section{Referências}

ANHANGUERA. Pedagogia - Licenciatura. Belo Horizonte: Kroton, 2016.

Disponível em: <http://anhanguera.com/graduacao/cursos/pedagogia-licenciatura. php>. Acesso em: 19 maio 2016.

ALCÂNTARA, Norma. Lukács: ideologia e alienação. São Paulo: Instituto Lukács, 2014.

CODO, Wanderley. O que é alienação. São Paulo: Brasiliense, 1985.

FREIRE, Paulo. Educação e mudança. 7. ed. São Paulo: Paz e Terra, 1983.

. Pedagogia da autonomia: saberes necessários a pratica educativa. 31. ed. São

Paulo: Paz e Terra. 2005.

GIROUX, Henry. Escola crítica e política cultural. 3. ed. São Paulo: Cortez, 1992.

LESSA, Sergio. Para compreender a ontologia de Lukács. 3. ed. Ijuí: Unijuí, 2012.

LUKÁCS, György. Para uma ontologia do ser social. v. 2. Tradução Nélio Schneider, Ivo Tonet, Ronaldo Vielmi Fortes. São Paulo: Boitempo, 2013.

NÓVOA, António. Formação de professores e profissão docente. In: . (Coord.).

Os professores e a sua formação. Lisboa: Dom Quixote, 1992. p. 13-33.

PIMENTA, Selma Garrido. Formação de professores: identidade e saberes da docência. In: . (Org.). Saberes pedagógicos e atividade docente. São Paulo: Cortez, 1999. p. $15-34$. 
SAVIANI, Dermeval. Pedagogia histórico-crítica. 9. ed. Campinas: Autores Associados, 2005.

UNIVERSIDADE ESTADUAL DE PONTA GROSSA (UEPG). Licenciatura em Pedagogia - UAB. Perfil do Curso. Ponta Grossa: UEPG, 2016. Disponível em: $<$ https://ead.uepg.br/apl/curso_polo/index.php?page=CursoPerfil\&ent=19>. Acesso em: 19 maio 2016.

Recebido em I5 ago. 2018 / Aprovado em I5 out. 2018 Para referenciar este texto:

SANTOS, A. R. J.; GONÇALVES, J. A.; COSTA, R. A formação do pedagogo na educação a distância: alguns dilemas e possibilidades. EccoS - Revista Científica, São Paulo, n. 47, p. 301-316. set/dez. 2018. Disponível em: <https://doi.org/10.5585/ EccoS.n47.7693>. 